\title{
Autosomal recessive ataxia due to ubiquinone deficiency
}

INSERM

\section{Source}

INSERM. (1999). Orphanet: an online rare disease and orphan drug data base. Autosomal recessive ataxia due to ubiquinone deficiency. ORPHA:139485

This syndrome is characterised by childhood-onset progressive ataxia and cerebellar atrophy. 